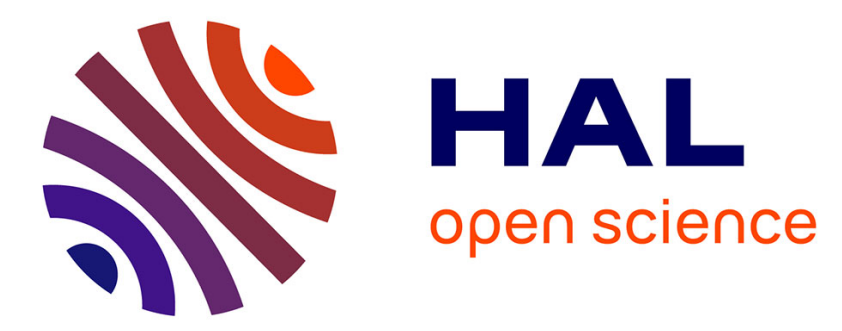

\title{
Pore morphology changes under tillage and no-tillage practices
}

Fabien Hubert, Vincent Hallaire, Paul Sardini, Laurent Caner, Djilali Heddadj

\section{To cite this version:}

Fabien Hubert, Vincent Hallaire, Paul Sardini, Laurent Caner, Djilali Heddadj. Pore morphology changes under tillage and no-tillage practices. Geoderma, 2007, 142 (1-2), pp.226-236. 10.1016/j.geoderma.2007.08.017 . hal-00246885

\section{HAL Id: hal-00246885 \\ https://hal.science/hal-00246885}

Submitted on 8 Feb 2008

HAL is a multi-disciplinary open access archive for the deposit and dissemination of scientific research documents, whether they are published or not. The documents may come from teaching and research institutions in France or abroad, or from public or private research centers.
L'archive ouverte pluridisciplinaire HAL, est destinée au dépôt et à la diffusion de documents scientifiques de niveau recherche, publiés ou non, émanant des établissements d'enseignement et de recherche français ou étrangers, des laboratoires publics ou privés. 


\title{
Pore morphology changes under tillage and no-tillage practices
}

\author{
HUBERT Fabien ${ }^{1 *}$, HALLAIRE Vincent ${ }^{2}$, SARDINI Paul ${ }^{1}$, CANER Laurent \\ ${ }^{1}$, HEDDADJ Djilali ${ }^{3}$
}

\section{Accepted version : Geoderma, 2007, 142, (1-2), 226-236}

${ }^{1}$ CNRS UMR 6532 Hydrogéologie, Argiles, Sols et Altérations. Université de Poitiers, 40 avenue du Recteur Pineau, 86022 Poitiers cedex, France.

${ }^{2}$ UMR Sol Agronomie Spatialisation, Agrocampus-INRA. 65 rue de Saint-Brieuc, CS 84215, 35042 Rennes cedex, France.

${ }^{3}$ Chambre d'agriculture de Bretagne. Avenue du Général Borgnis Desbordes, BP 398, 56009 Vannes cedex, France.

* Corresponding author: mail. fhubert@etu.univ-poitiers.fr, tel. +33 5494538 67, fax: +33 549454241 .

\begin{abstract}
The relative influence of biological and mechanical processes on the structure of cultivated soils was estimated by investigating the macroporosity of the surface layers of a silty soil during a maize growing season. The soil was subjected to different cultivation techniques (conventional tillage, moderate tillage, and no tillage) and fertilization modes (mineral or organic) for five years. A typological model was developed (i) to identify the macropores by 2D image analysis in undisturbed soil samples, and (ii) to characterize their morphology with two shape parameters (elongation and regularity indexes). Based on the three usual pore categories (tubular, planar and packing pores), five groups were defined with an additional distinction within the packing pore category (discrete, continuous and planar packing). This typology, as based on a set of images that reached the representative elementary area (REA), proved appropriate to describe the structural modifications linked to the crop management practices. It was shown that mechanical soil working produces 'continuous packing pores' whereas the absence of work induces 'discrete packing pores'. The study of the intra-annual
\end{abstract}


structural dynamics enabled the identification of the processes responsible for those modifications. With conventional tillage, the progressive substitution of continuous packing pores with discrete packing pores can be interpreted as the resumption of biological fragmentation after mechanical fragmentation (harrowing). Without management, the soil is only subjected to biological fragmentation, so neither quantitative nor morphological evolution of the macroporosity was observed during the growing season, with the soil structure depending more on spatial heterogeneity than on seasonal changes.

Key words: no tillage, reduced tillage, image analysis, pattern recognition, representative elementary area. 


\section{Introduction}

Soil quality is closely related to soil structure and can be directly influenced by environnemental damage in intensive arable lands, such as erosion, desertification or susceptibility to compaction (Pagliai et al., 2004). Results from field experiments usually recommend adoption of reduced tillage practices to prevent soil structural degradation and reveal beneficial long-term effects on physical, chemical and biological soil properties (Unger et al., 1991; Hubbard et al., 1994; Karlen et al., 1994). According to different authors, reduced tillage practices have opposite effects on topsoil structural and biological properties, depending on soil type and climatic conditions. Reduced tillage affords limitation of erosion by increasing structural stability and resistance against stress from vehicle load (Tebrügge and Düring, 1999; Rasmussen, 1999) and by permitting the development of earthworm community (Cluzeau et al., 1999). It is reported, however, that reduced tillage practices raise soil compaction (Stengel, 1986) inducing a decrease in macrofauna activity (Whalley et al., 1995) as well as in air and water infiltration (Rasmussen, 1999).

It is well assumed that cultural practices mainly affect macroporosity, i.e. pores larger than 30 $\mu \mathrm{m}$ (in diameter) that can be formed by soil tillage, soil fauna and roots of crops (Lipiec and Hatano, 2004). Image analysis of polished sections has been used to quantify soil pore size distribution, and to characterize the irregularity, orientation and shape of the pores (RingroseVoase, 1984, 1990). This technique was employed by Vandenbygaart (1999) and Lamandé et al (2003) to study changes in soil structure between conventional tillage and no tillage agricultural practices.

Two-dimensional image analysis of shape, size and continuity of macroporosity allows to characterise the processes affecting soil physical properties (Ringrose-Voase and Bullock, 1984). The primary factors that affect soil structure under cultivation can be separated in two major processes; the first one corresponding to mechanical fragmentation by ploughing and biological fragmentation by earthworms involving soil decompaction, and the second one referring to settling through wheel-traffic and natural settling that compact the soils. In cultivated silty soils, due to low contents in clay and ploughing, the shrinking and swelling of aggregates which is also a primary factor of soil structure is negligible.

The decompacting processes increase macroporosity whereas the compacting processes decrease it. It is widely admitted that under cultivated these two processes act essentially on the "packing voids” resulting from the loose packing of aggregates (Brewer, 1964, RingroseVoase, 1987). However, as "packing voids” correspond to a cluster of pores with a large 
variety of morphologies, more or less continuous with variable width and nonaccommodating faces, it is difficult to characterise and quantify the role of each elementary factor of soil structure.

The aim of the present study was to improve the distinction between the biological and mechanical origins of packing voids, using image analysis techniques, by developing a typological parametric model based on shape indexes. This model was subsequently applied to analyse the structural evolution of the soil surface layers under three different agricultural managements (i.e. conventional tillage, moderate tillage and no tillage) during a maize growing season.

\section{Materials and Methods}

\section{Experimental design and sampling}

The site is located at the experimental station of Kerguehennec in western Brittany, France. The soil, derived from mica schist, is a Humic Cambisol (FAO) with a loamy texture and a high organic matter content in the first $25 \mathrm{~cm}$ (Table 1). The field experiment, established in 2000, is composed of 3 plots $(12 \mathrm{~m} \times 25 \mathrm{~m})$ under mineral fertilisation with 3 tillage practices considered: (i) conventional tillage (CT), with ploughing at the depth of $25 \mathrm{~cm}$ and harrowing at a depth of $5 \mathrm{~cm}$ before sowing; (ii) moderate tillage (MT), with harrowing at a depth of 5 to $7 \mathrm{~cm}$; and (iii) no tillage (NT) with harrowing of the seedbed at the depth of $8 \mathrm{~cm}$ upon sowing only. Tillage and sowing operations were performed at the end of April 2004.

Undisturbed soil blocks (16 cm high $\times 9 \mathrm{~cm}$ wide $\times 5 \mathrm{~cm}$ deep) were collected near the noncompacted maize inter-row zone from the three tillage practices during the growing season at 9 different dates between sowing (May) and harvesting (November). For each tillage practice, the trial comprised 16 sampling with seven undisturbed blocks for a depth ranging from 1 to 7 cm (3 in May, 2 in June, 1 in July and 1 in September), and nine for a depth ranging from 10 to $16 \mathrm{~cm}$ (1 in April and 1 in November) (Fig. 1a). After removal of water with acetone, soil samples were impregnated under vacuum with a polyester resin containing a fluorescent dye (Uvitex) (Ringrose-Voase, 1996). The impregnated blocks were cut vertically in two polished sections $(16 \mathrm{~cm}$ high $\times 9 \mathrm{~cm}$ wide $\times 1 \mathrm{~cm}$ thick) in their centre and three faces where analysed (Fig. 1b). 
Image generation, segmentation and representative elementary area (REA)

The polished sections were digitized under reflected ultra-violet light (365 nm) using a digital Nikon D100 camera at a resolution of $2000 \times 3008$ pixels. The solid phase appears in dark colours whereas macroporosity appears in bright colours. The parameters of the digital camera were adjusted to optimize contrast between the solid aggregates and the macroporosity. Then, a good discrimination of the solid phase and the macroporosity was possible employing a simple upper limit threshold.

Nevertheless, quartz and feldspar may react under reflected ultra-violet light and lead to an overestimation of the macroporosity. In order to subtract this artefact, the polished sections were also digitized under reflected natural light under which only these minerals react. All digital image sizes were adjusted to 1700 (in height) $\times 2500$ (in width) pixels for removing the sampling-induced side effects. The pixel area was $900 \mu \mathrm{m}^{2}$, so the image was $5.1 \mathrm{~cm}$ in height and $7.5 \mathrm{~cm}$ in width. The digitized images were analysed using the Noesis Visilog 6.3 software. The images captured under reflected natural light with spectral resolution of 256 grey levels were segmented by a upper limit threshold. The resultant binary images were filtered using mathematical morphology operators, i.e. erosion following by a geodesic reconstruction (Serra, 1982). After filtration, only the reacting minerals in white (quartz and feldspar) appeared in the resulting images. These images were then subtracted from the binary images previously captured and segmented from under reflected ultra-violet light. In the final binary image, poroids (i.e. the representation of a pore in polished sections as defined by Moran et al., 1988) with less than 50 pixels were removed because their shape was insufficiently resolved for analysis (Ringrose-Voase and Bullock, 1984). Ultimately, the remaining poroids on the binary image were labelled for individual shape analysis.

To determine the Representative Elementary Area (REA) we employed the method proposed by VandenBygaart and Protz (1999). The parameter was measured on 16 image frames of sequential sizes centred on the centre pixel of the full image (Table 2). The REA is attained at the area where the measurements made on a parameter in three successive areas do not change by more than $10 \%$ relative to the next greater area of measurement.

When the total (?) analysed area was larger than the REA for the studied parameters, the values obtained were considered as independent of the size of the thin section (Bear, 1972), and thus was validated for further analysis.

For each pore shape class, the two parameters used were the total macroporosity and the macroporosity, which were defined as follows: 
total macroporosity $(\%)=\frac{\text { Number of macroporosity pixels }}{\text { Total number of image pixels }}$

class macroporosity $(\%)=\frac{\text { Number of shapeclass pixels }}{\text { Total number of image pixels }}$

\section{Parameterisation of poroid shape}

The shape of a poroid was characterized by two size-independent indexes (i.e. dimensionless; Coster and Chermant, 1989): regularity and elongation indexes.

The regularity index Ic(p) (with (p) for poroid) is the ratio of the convex perimeter $\mathrm{P}(\mathrm{Cv}(\mathrm{p})$ ) to the poroid perimeter $\mathrm{P}(\mathrm{p})$ (Fig. 2):

Ic $(\mathrm{p})=\frac{\mathrm{P}(\mathrm{Cv}(\mathrm{p}))}{\mathrm{P}(\mathrm{p})}$

The convex perimeter was calculated as defined by Ringrose-Voase and Bullock (1984):

$\mathrm{P}(\mathrm{Cv}(\mathrm{p}))=\left(\frac{\Pi}{\mathrm{N}}\right) \times \sum_{i=1}^{\mathrm{N}}$ (Feret diameters $)$

with $\mathrm{N}=$ number of Feret diameters (calculated for 10 angles)

The poroid perimeter $\mathrm{P}(\mathrm{p})$ is equivalent to the Crofton perimeter. The regularity index tends to 1 as the poroid shape tends to a convex shape.

The elongation index IGg (p) is based on the calculation of the geodesic length defined as the maximal geodesic distance between any two points located within a poroid (Fig. 2) (Lantuejoul and Maisonneuve, 1984). The elongation index was obtained as follows:

$$
\operatorname{IGg}(\mathrm{p})=\frac{\Pi \times \operatorname{Lg}(\mathrm{p})^{2}}{4 \times \mathrm{A}(\mathrm{p})}
$$

with $\operatorname{Lg}(\mathrm{p})$ the geodesic length and $\mathrm{A}(\mathrm{p})$ the poroid area.

The elongation index is independent of the perimeter roughness of the poroid. The elongation index is equal to 1 when the poroid is a disk and increases when the poroid extends (i.e. deviates from a disk).

\section{Poroid shape classes and typological model creation}

In order to identify classes of different poroid shapes found under various tillage treatments, a parametrical model based on the two shape indexes was created. A poroid data set was derived from polished sections (i) from this study, (ii) from other loam soils under grassland 
(Lamandé et al., 2003) and (iii) from clay soils under wheat (Hallaire, 1994). A total of 1465 typical poroids were selected and separated manually into 5 classes (Fig. 3) as follows:

- tubular poroids (T): near-circle shape (441 poroids) (Fig. 3-T),

- planar poroids (p): elongated shape without connection with other poroids (298 poroids) (Fig. 3-p),

- discrete packing poroids (Pd): complex shape without connection with other poroids in 2D (387 poroids) (Fig. 3-Pd),

- planar packing poroids (Pp): association of variously-shaped poroids by planar connexion (245 poroids) (Fig. 3-Pp),

- continuous packing poroids (Pc): complex association of variously-shaped poroids through discrete packing poroids (94 poroids) (Fig. 3-Pc).

On Fig. 4 the elongation index was plotted against the regularity index; the distribution of the 1465 selected poroids indicates that these two indexes are relevant to discriminate between the five classes defined above. A statistically significant difference between the five defined classes was confirmed by a non parametric test on rank (Kruskal-Wallis, $\mathrm{p}=0.05$ ), except for Pp and Pd classes with the regularity index. The limit between two areas of shape classes (T, p, Pd, Pp and Pc) were manually defined and marked by straights lines on Fig 4 in order that each area contains the maximum number of poroids of the same class with the less poroids of another class. The large variety of poroid shapes and the presence of intergrades (RingroseVoase, 1996) are represented graphically (Pc/T, $\mathrm{Pp} / \mathrm{Pc}, \mathrm{p} / \mathrm{Pp})$ where two previous classes are mixed.

\section{Results}

Of the 144 images analysed, 86 images (60 \%) reached the REA for the total macroporosity measurement but only 41 (28.5 \%) for the class macroporosity measurement. As a result, the number of representative images was too small to study the macroporosity evolution for all the sampling dates. The mean decrease of the total macroporosity after filtration and removing of insufficiently resolved poroids is $4.1 \%$ (more and less $3.0 \%$ ).

Comparison of shape classes' identification: typological model versus circularity parameter Fig. 5 presents three binary soil images (macroporosity is in white) and the associated macroporosity class distribution using the circularity parameter (thresholds from Lamandé et 
al., 2003) and using the typological model created. The three images show contrasted proportions of total macroporosity and morphology. "Image a”, corresponding to CT at $1 \mathrm{~cm}$ deep, presents a high total macroporosity (33.4\%) with numerous continuous packing poroids and some small tubular and discrete packing poroids. The typological model indicates that continuous packing poroids account for $3 / 4$ of the total macroporosity and the last quarter is composed by the two other classes (T and Pd). “Image b”, corresponding to MT at $10 \mathrm{~cm}$ deep, presents a low total macroporosity (8.7\%). The typological model attributes mainly this macroporosity to small tubular, planar poroids, and 2/3 of the total macroporosity correspond to bigger discrete packing poroids. “Image c”, under NT at $1 \mathrm{~cm}$ deep, presents a total macroporosity (16.3\%) intermediate between those of the two previous images. A big planar packing poroid crosses the image with tubular and discrete packing poroids of various sizes all around. Nearly half of the total macroporosity is attributed by the typological model to planar packing poroids and the remaining poroids are distributed between tubular and discrete packing poroids. With the circularity parameter, packing poroids are mainly dominants for “images a” (27.8 \%) and “image c” (10.4 \%) and weakly dominants for “image b” (3.7 \%). Moreover, the proportion of tubular poroids is comparable with the typological model calculation for the three binary images. The macroporosity class distribution with the circularity parameter allows to highlight changes in quantity of packing poroids. Nevertheless, this classification doesn't discriminate the real shape variations which mainly occur in the packing poroid class for silty cultivate soils under different treatments.

Fig. 6 illustrates the results given by the typological model on the "image a” and "image c", of figure 5, and shows noticeable differences in the distribution within the poroid shape classes, especially in the Pc and Pp classes. Whatever the tillage practice used, the soil structure (macroporosity) is dominated by packing and tubular poroids whereas the other classes can be considered as negligible. However, despite prevailing packing poroids for all three treatments, the typological model highlighted differences in their morphology (Fig. 5) that can be attributed to different origins, and particularly cracks (Fig. 5c) resulting from shrinkage.

\section{Morphological characterisation under different treatments after two months}

The morphology of the total macroporosity was analysed during the vegetal cycle (June 28). The results are reported in figure 7. Significant variations in total macroporosity and morphology are observed as well as between the different tillage practices and the two depths, 1-7 $\mathrm{cm}$ and $10-16 \mathrm{~cm}$. 
Under CT (Fig. 7a), total macroporosity values are high at both depths, i.e. $38.3 \%$ at $1-7 \mathrm{~cm}$ and $24.5 \%$ at $10-16 \mathrm{~cm}$, respectively. The difference is due to harrowing for seedbed preparation at $5 \mathrm{~cm}$ deep. The macroporosity is mainly dominated by continuous packing poroids and less than $5 \%$ (absolute value) correspond to discrete packing and tubular poroids. Under MT (Fig. 7b), the high total macroporosity value at the soil surface (27.4\%) and the class distribution are similar to the results obtained under CT. However, a larger contribution of the discrete packing and tubular poroids is noted (7 \%). At 10-16 cm deep, the decrease in the total macroporosity to $11.1 \%$ corresponds to a loss of continuous packing poroids.

Under NT (Fig. 7c), the total macroporosity is low, i.e. $9.1 \%$ and $7.7 \%$ at $1-7 \mathrm{~cm}$ and $10-16$ cm deep, respectively. Discrete packing and tubular poroids are the dominant classes at both depths, and at the soil surface, planar packing poroids account for up to $20 \%$ of the total macroporosity.

\section{Macroporosity evolution during the growing season}

A comparison was possible between June and September under conventional tillage (Fig. 8a) and between May and September without management (NT) (Fig. 8b), at both studied depths. The data used to make figure 6 correspond to the mean of the values obtained using the shape parameters on each image of the three polished sections made from the same block. Standard deviations are also plotted in the figure. Despite the fact that three images are not sufficient to make statistics, image analyses are usually performed on one unique polished section.

Under CT, the poroid morphology changes considerably between June and September (Fig. 8a) without any significant variation in total macroporosity (about $30 \%$ at $1-7 \mathrm{~cm}$ deep and about $20-25 \%$ at $10-16 \mathrm{~cm}$ deep). The mean value of continuous packing poroids strongly decreases from $26.0 \%$ to $17.1 \%$ at $1-7 \mathrm{~cm}$ deep and from 15.1 to $9.5 \%$ at $10-16 \mathrm{~cm}$ deep while the mean value of discrete packing poroids increases at $1-7 \mathrm{~cm}$ deep from $2.8 \%$ to 8.2 $\%$ and from $3.1 \%$ to $7.6 \%$ at $10-16 \mathrm{~cm}$ deep. The other classes do not exhibit significant variations.

Without soil management, the total macroporosity is less than $10 \%$ and there is no variation between May and September at both depths (Fig. 8b). The dominant morphological classes are tubular (3\%) and discrete packing poroids (4\%). However, the standard deviation of the classes between the two dates is too large to validate the variation of the class macroporosity values. 


\section{Discussion and conclusion}

Two situations can be distinguished considering tillage practices and depth. Under CT at both depths (Fig. 7a) and under MT at the soil surface (Fig. 7b), the total macroporosity is two to five times higher than under NT at both depths and under MT in depth (Fig. 7b and 7c). After four years under no tillage, the macroporosity decrease, as it was observed by different authors (Stengel, 1986; Tebrügge and Düring, 1999; Rasmussen, 1999).

The poroid shape is usually defined by a circularity index that differs between authors but which is more often estimated by the ratio of the poroid area to its perimeter (Bouma et al., 1977; Lamandé et al, 2003; Pagliai et al., 2004). Other authors use two indexes (irregularity and elongation indexes) to describe the morphology of macropores (Ringrose-Voase and Bullock, 1984; Zida, 1998). However these different approaches led to the distinction of three main classes of poroids: tubular poroids, cracks and packing poroids, with the packing poroids being usually dominant under tillage practices (Fig. 5). In this work, we used the same kind of indexes (elongation, regularity) to better discriminate the broad class of packing poroids in subclasses. However, we employed a specific elongation index which is based on the calculation of the geodesic length of each poroïd. Contrary to perimeter-based indexes such as circularity index, this index is insensitive to the roughness of poroïd perimeter; in other terms, it is a most robust parameter as regards thresholding and filtering processes which controlling strongly poroïd perimeter. This study is the first to propose a typological model that enables the packing poroids to be described in more details and to be divided into three subclasses: planar packing poroids, discrete packing poroids and continuous packing poroids.

This work reveals that under tillage, within the packing poroid class, the continuous packing poroids are largely dominant, while the discrete packing and the tubular poroids are less abundant. Under no tillage, the morphological distribution is completely different, with discrete packing and tubular poroids becoming dominant classes and other classes becoming weak, except for planar packing poroids (Fig. 7 and 8).

Moreover, the method developed in this study advantageously allows for the follow-up of the soil structure evolution during a growing season (Fig. 8). Under CT (Fig. 8a), the continuous packing poroids decrease and the discrete packing poroids increase, without significant decrease in total macroporosity. In June, mechanical fragmentation and natural settling have already occurred (Mackie-Dawson et al., 1989). Optimal burrowing activity is most pronounced in spring and autumn when the soil water content increases (Evans and Guild, 1947) but earthworm burrowing activity displacements are facilitated by ploughing. The 
images obtained under conventional tillage between June and September show the obvious action of earthworms with the presence of cashes within burrows (Fig. 9).The morphological variation may be attributed to the biological fragmentation by earthworms. The continuous packing poroids decrease by $1 / 3$ at $1 \mathrm{~cm}$ and $10 \mathrm{~cm}$ deep whereas the discrete packing poroids are multiplied by 3 at $1 \mathrm{~cm}$ deep and by 2.5 at $10 \mathrm{~cm}$ deep.

Without soil management, biological fragmentation by the earthworm activity is dominant and produces mainly discrete packing poroids and tubular poroids (Fig. 8b). During the growing season, neither quantitative nor morphological variations in macroporosity are observed. The low macroporosity under NT limits the earthworm burrowing activity, which is confined to the already existing burrows. The high standard deviation values for the various shape classes indicate that under NT, the morphological variation in macroporosity is linked more to spatial than temporal variability.

Using the model, we associated the dominant shape classes to soil structure formation factors: - continuous packing poroids correspond to the mechanical tillage.

- discrete packing poroids, similar to vughs (Brewer, 1964), that are usually attributed to setlling processes (Ringrose-Voase, 1987) are generated by biological fragmentation (VandenBygaart et al., 2000).

- planar packing poroids that correspond to one part of the crack classe of Ringrose-Voase (1984) (the other part is represented by planar poroids) arise from physical fragmentation induced by shrinkage and swelling. The typological model created takes into account these classes of macroporosity, however the low proportion of planar packing poroids demonstrates that these phenomenon are negligible under silty cultivated top soil.

The present study provides a more sensitive image analysis tool for assessing the effect of agricultural managements on the soil structure than the other models with three classes that are not directly adapted to cultivated top soils. These results indicate that $2 \mathrm{D}$ poroid morphology analysis is a sensitive tool to identify and quantify the mechanical and biological structuration factors that occur under conventional tillage at the time scale of the growing season with a limited data set of polished sections. However, the method is less efficient under no tillage due to the spatial variability. The 3D characterisation of porosity (i.e. X-Ray Tomography) could be a valuable tool to identify the biologically-induced morphological variations (De Gryze et al., 2006). 


\section{Acknowledgements}

The technical assistance of Y. Benard, UMR Sol Agronomie Spatialisation, for the preparation of polished section is gratefully acknowledged.

\section{References}

Bear, J., 1972. Dynamics of Fluids in Porous Media. Elsevier, New York, 764 pp.

Bouma, J., Jongerius, A., Boersma, O., Jager, A. and Schoonderbeek, D., 1977. The Function of Different Types of Macropores During Saturated Flow through Four Swelling Soil Horizons. Soil Science Society of America Journal, 41: 945-950.

Brewer, R., 1964. Fabric and Mineral Analysis of Soils. John Wiley and Sons, New York, 470 pp.

Cluzeau, D., Cannavacciulo, M. and Péres, G., 1999. Indicateurs macrobiologiques des sols : les lombriciens - Méthode d'échantillonnage dans les agrosystèmes en zone tempérée. Dans : $12^{\text {ème }}$ Colloque Viticole et Enologique. Ed. ITV Paris. pp. 25-35.

Coster, M. and Chermant, J.L., 1989. Précis d'analyse d'images. Edition du CNRS, Paris, 560 pp.

Czachor, H. and Lipiec, J., 2004. Quantification of soil macroporosity with image analysis. International Agrophysics, 18: 217-223.

De Gryze, S. Jassogne, L, Six J., Bossuyt H., Wevers, M, Merckx, 2006, Pore structure changes during decomposition of fresh residue: X-ray tomography analyses, Geoderma, 134, 82-96).

Evans, A.C. and Guild, W.J.M., 1947. Studies on the relationships between earthworm and soil fertility. 1. Biological studies in the field. Annals of Applied Biology, 24: 307-330.

Hallaire, V., 1994. Description of microcrack orientation in a clayey soil using image analysis. in: Soil Micromorphology: Studies in Management and Genesis. Proceedings of the IX International Working Meeting on Soil Micromorphology. Ed. A.J. RingroseVoase and G.S. Humphreys., pp. 549-557. Developments in Soil Science, 22, Elsevier, Amsterdam.

Hubbard, R.K., Hargrove, W.L., Lowrance, R.R., Williams, R.G. and Mullinix, B.G., 1994. Physical properties of a clayey coastal plain soil as affected by tillage. Journal of Soil and Water Conservation, 49: 276-283. 
Karlen, D.L., Wollenhaupt, N.C., Erbach, D.C., Berry, E.C., Swan, J.B., Eash, N.S. and Jordalhl, J.L., 1994. Long-term tillage effects on soil quality. Soil and Tillage Research, 32: $313-327$.

Lamandé, M., Hallaire, V., Curmi, P., Peres, G. and Cluzeau, D., 2003. Changes of pore morphology, infiltration and earthworm community in a silty soil under different agricultural managements. Catena, 54: 637-649.

Lantuejoul C. and Maisonneuve F., 1984, Geodesic methods in quantitative image analysis, Pattern Recognition, 17-2: 177-187.

Lipiec J. and Hatano R., 2003. Quantification of compaction effects on soil physical properties and crop growth. Geoderma, 116: 107-136.

Mackie-Dawson, L.A., Mullins, C.E., Fitzpatrick, E.A. and Court, M.N., 1989. Seasonal changes in the structure of clay soils in relation to soil management and crop type. Effects of crop rotation at Cruden Bay, NE Scotland. Journal of Soil Science, 40: 269281.

Moran, C.J., Koppi, A.J., Murphy, B.W. and McBratney, A.B., 1988. Comparaison of the macropore structure of a sandy loam surface soil horizon subjected to two tillage treatments. Soil Use and Management, 4: 96-102.

Pagliai, M., Vignozzi, N. and Pellegrini, S., 2004. Soil structure and the effect of managementpractices. Soil \& Tillage Research, 79: 131-143.

Rasmussen, K.J., 1999. Impact of ploughless soil tillage on yield and soil quality : A Scandinavian review. Soil \& Tillage Research, 53: 3-14.

Ringrose-Voase, A.J., 1987. A scheme for the quantitative description of soil macrostructure by image analysis. Journal of Soil Science, 38: 343-356.

Ringrose-Voase, A.J., 1990. One-dimensional image analysis of soil structure. II. Interpretation of parameters with respect to four forest soil profiles. Journal of Soil Science, 41: 513-527.

Ringrose-Voase, A.J., 1996. Measurement of soil macropore geometry by image analysis of sections through impregnated soil. Plant and Soil, 183: 27-47.

Ringrose-Voase, A.J. and Bullock, P., 1984. The automatic recognition and measurement of soil pore types by image analysis and computer program. Journal of Soil Science, 35: 673-684.

Serra, J., 1982. Image analysis and mathematical morphology. Academic Press, London, 610pp. 
Stengel, P., 1986. Simplification du travail du sol en rotation céréalière : conséquences physiques. Dans : Les rotations céréalières intensives - Dix années d’études concertées INRA, ONIC, ITCF 1973-1983. Ed. INRA Paris. pp. 15-44.

Tebrügge, F. and Düring, R.A., 1999. Reducing tillage intensity - a review of results from a long-term study in Germany. Soil \& Tillage Research, 53: 15-28.

Unger, P.W., Stewart, B.A., Parr, J.F and Singh, R.P., 1991. Crop residue management and tillage methods for conserving soil and water in semi-arid regions. Soil \& Tillage Research, 20: 219-240.

VandenBygaart, A.J. and Protz, R., 1999. The representative elementary area (REA) in studies of quantitative soil micromorphology. Geoderma, 89: 333-346.

VandenBygaart, A.J., Protz, R., and Tomlin, A.D., 1999. Changes in pore structure in a no-till chronosequence of silt loam soils, southern Ontario. Canadian journal of Soil Science, 79: $149-160$

Vandenbygaart, A.J., Fox, C.A., Fallow, D.J. and Protz, R., 2000. Estimating earthworminfluence soil structure by morphometric image analysis. Soil. Sci. Soc. AM. J., 64: 982-988.

Whalley, W.R., Dumitru, E. and Dexter, A.R., 1995. Biological Effects of Soil Compaction. Soil \& Tillage Research, 35: 53-68.

Zida, M., 1998. Structure et fonctionnement hydrique d'un système pédologique armoricain (France). Rôle de l'espace poral et de l'agencement des horizons. Ph.D. Thesis, Ecole Nationale Supérieure Agronomique de Rennes, France. 


\section{Tables}

Table 1: Soil physico-chemical characteristics

\begin{tabular}{cccccccc}
\hline $\begin{array}{c}\text { Depth } \\
(\mathrm{cm})\end{array}$ & $\begin{array}{c}<2 \mu \mathrm{m} \\
(\%)\end{array}$ & $\begin{array}{c}2-20 \mu \mathrm{m} \\
(\%)\end{array}$ & $\begin{array}{c}20-50 \mu \mathrm{m} \\
(\%)\end{array}$ & $\begin{array}{c}50-200 \\
\mu \mathrm{m}(\%)\end{array}$ & $\begin{array}{c}200-2000 \\
\mu \mathrm{m}(\%)\end{array}$ & $\mathrm{pH}$ & $\begin{array}{c}\mathrm{OM} \\
(\%)\end{array}$ \\
\hline $0-25$ & 16.6 & 23.3 & 19.1 & 26.0 & 15.0 & 6.0 & 4.3 \\
\hline $25-40$ & 16.0 & 25.0 & 17.9 & 26.5 & 14.4 & 5.4 & 2.5 \\
\hline $40-80$ & 13.7 & 19.9 & 15.7 & 28.0 & 21.6 & 5.0 & 1.2 \\
\hline
\end{tabular}

Table 2: Size of the 16 frames for determination of the representative elementary area

\begin{tabular}{ccccc}
\hline $\begin{array}{c}\text { Area } \\
(\text { pixel})\end{array}$ & $\begin{array}{c}\text { Width } \\
\text { (pixel) }\end{array}$ & $\begin{array}{c}\text { Length } \\
(\text { pixel })\end{array}$ & $\begin{array}{c}\text { Width } \\
(\mathrm{cm})\end{array}$ & $\begin{array}{c}\text { Length } \\
(\mathrm{cm})\end{array}$ \\
\hline 4250000 & 2500 & 1700 & 7.50 & 5.10 \\
\hline 3736336 & 2344 & 1594 & 7.03 & 4.78 \\
\hline 3255744 & 2188 & 1488 & 6.56 & 4.46 \\
\hline 2808224 & 2032 & 1382 & 6.10 & 4.15 \\
\hline 2393776 & 1876 & 1276 & 5.63 & 3.83 \\
\hline 2012400 & 1720 & 1170 & 5.16 & 3.51 \\
\hline 1664096 & 1564 & 1064 & 4.69 & 3.19 \\
\hline 1348864 & 1408 & 958 & 4.22 & 2.87 \\
\hline 1066704 & 1252 & 852 & 3.76 & 2.56 \\
\hline 817616 & 1096 & 746 & 3.29 & 2.24 \\
\hline 601600 & 940 & 640 & 2.82 & 1.92 \\
\hline 418656 & 784 & 534 & 2.35 & 1.60 \\
\hline 268784 & 628 & 428 & 1.88 & 1.28 \\
\hline 151984 & 472 & 322 & 1.42 & 0.97 \\
\hline 68256 & 316 & 216 & 0.95 & 0.65 \\
\hline 17600 & 160 & 110 & 0.48 & 0.33 \\
\hline
\end{tabular}




\section{Figures}

Figure 1: Schematic representation of sample preparation and dates of sampling: a-Dates of sampling ; b-Sample preparation.

a Sample dates for each tillage practice :

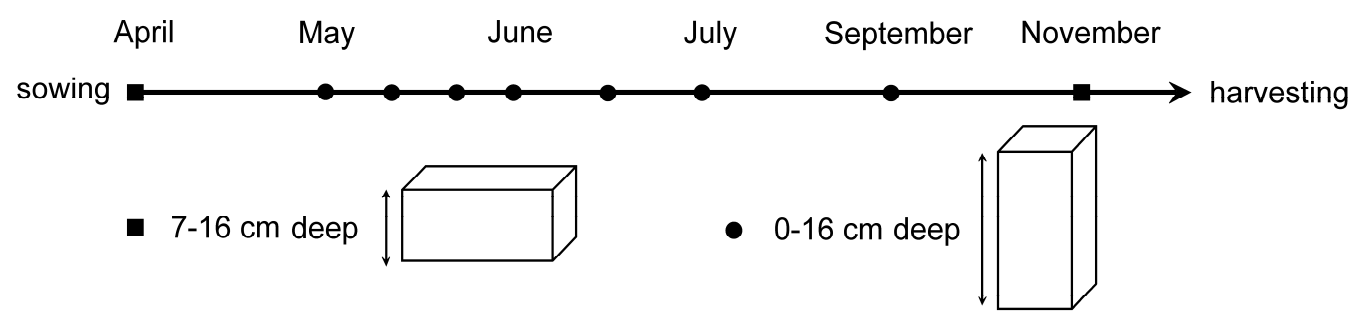

b Sample preparation :

undisturbed soil block

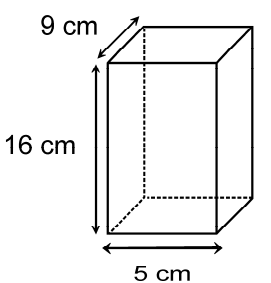

2 sections: 4 faces

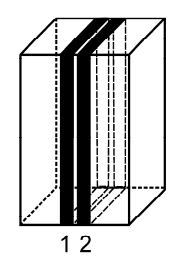

3 faces analysed

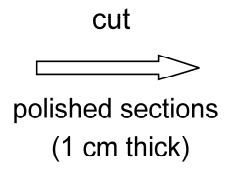

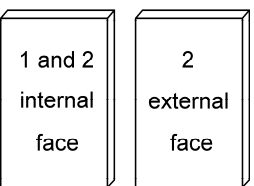

$9 \mathrm{~cm}$

Figure 2: Schematic representation of poroid shape parameters. $\mathrm{P}(\mathrm{p})$ poroid perimeter, $\mathrm{P}(\mathrm{Cv}(\mathrm{p}))$ convex perimeter, and $\mathrm{Lg}(\mathrm{p})$ geodesic length.

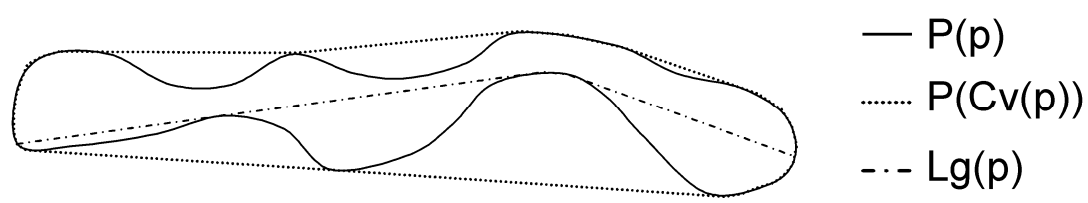


Figure 3: Examples of typical poroids selected to characterise the 5 morphological classes. T-Tubular poroids ; p-Planar poroids ; Pd-Discrete packing poroids ; Pp-Planar packing poroids ; Pc-Continuous packing poroids.
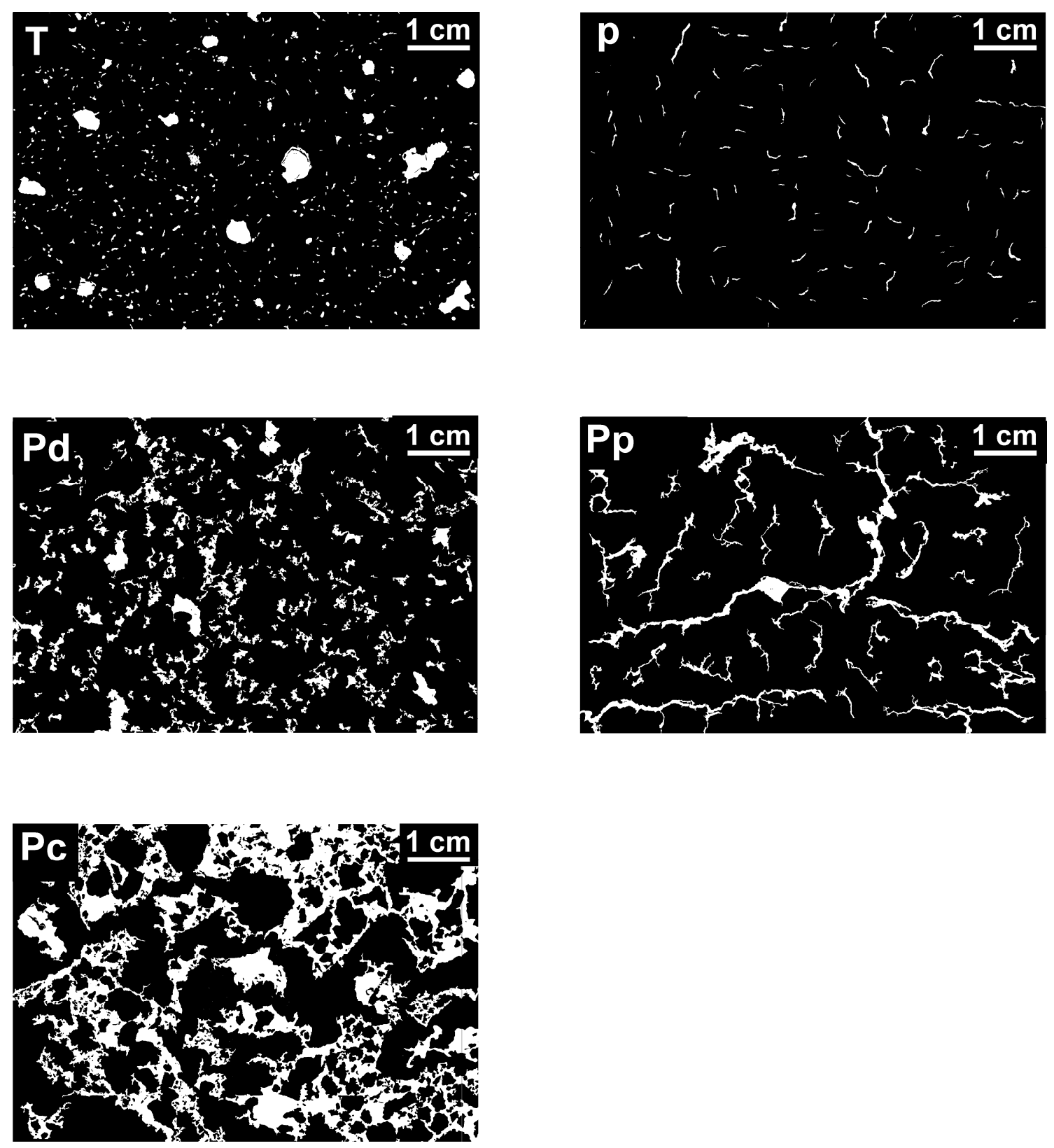
Figure 4: Typological model of shape identification. T-Tubular poroids; p-Planar poroids; Pd-Discrete packing poroids; Pp-Planar packing poroids; Pc-Continuous packing poroids; p/Pp-Intergrade planar and planar packing poroids; Pp/Pc-Intergrade planar packing and continuous packing poroids; Pc/T-Intregrade continuous packing and tubular poroids.

elongation index

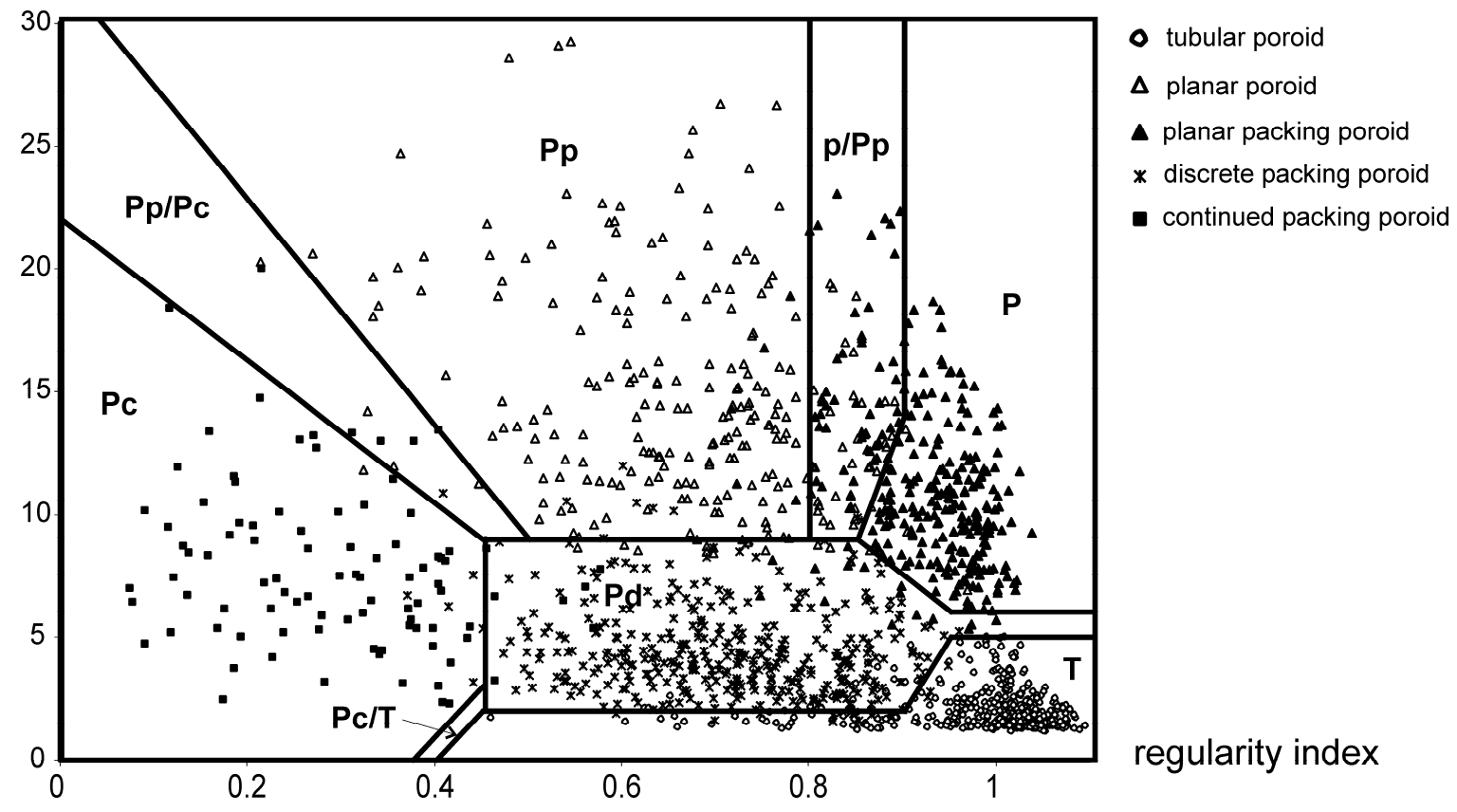


Figure 5: Binary images and associated macroporosity class distribution calculated by typological model created and by the circularity parameter. a-under conventional tillage at 1-7 cm deep ; b-under moderate tillage at 10-16 cm deep ; c-under no tillage at 1-7 cm deep. TM is Total Macroporosity. T-Tubular poroids ; p-Planar poroids ; Pp-Planar packing poroids ; Pd-Discrete packing poroids; Pc-continuous packing poroids ; Pc/T-Intregrade continuous packing and tubular poroids ; Pp/Pc-Intergrade planar packing and continuous packing poroids ; p/Pp-Intergrade planar and planar packing poroids.
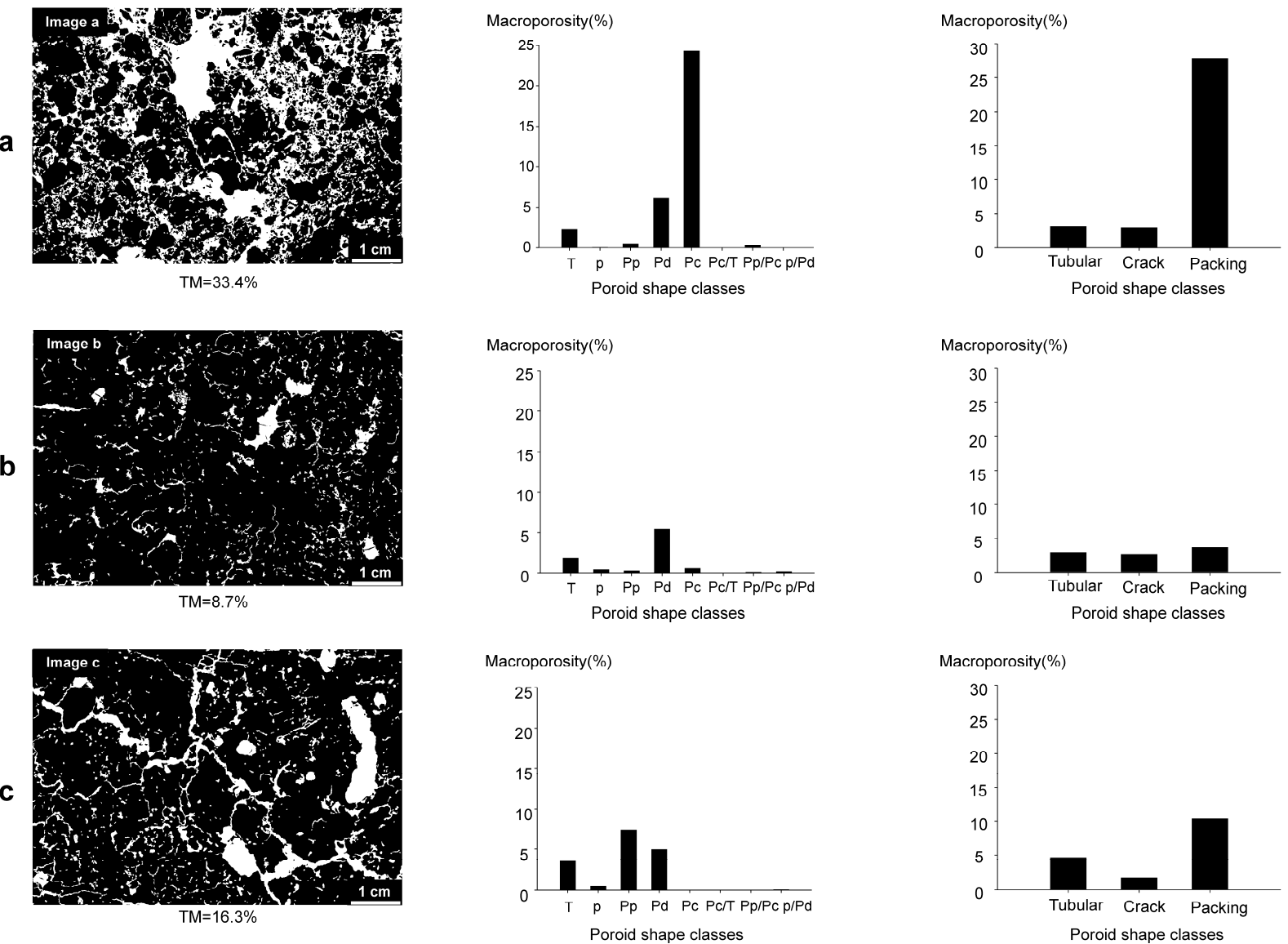
Figure 6: Examples of poroids selected for each class by the typological model in 2 binary images: "image a” under conventional tillage at 1-7 cm deep; “image c” under no tillage at 17 cm deep. T-Tubular poroids ; p-Planar poroids ; Pp-Planar packing poroids ; Pd-Discrete packing poroids ; Pc-continuous packing poroids ; Pc/T-Intregrade continuous packing and tubular poroids ; Pp/Pc-Intergrade planar packing and continuous packing poroids ; p/PpIntergrade planar and planar packing poroids.
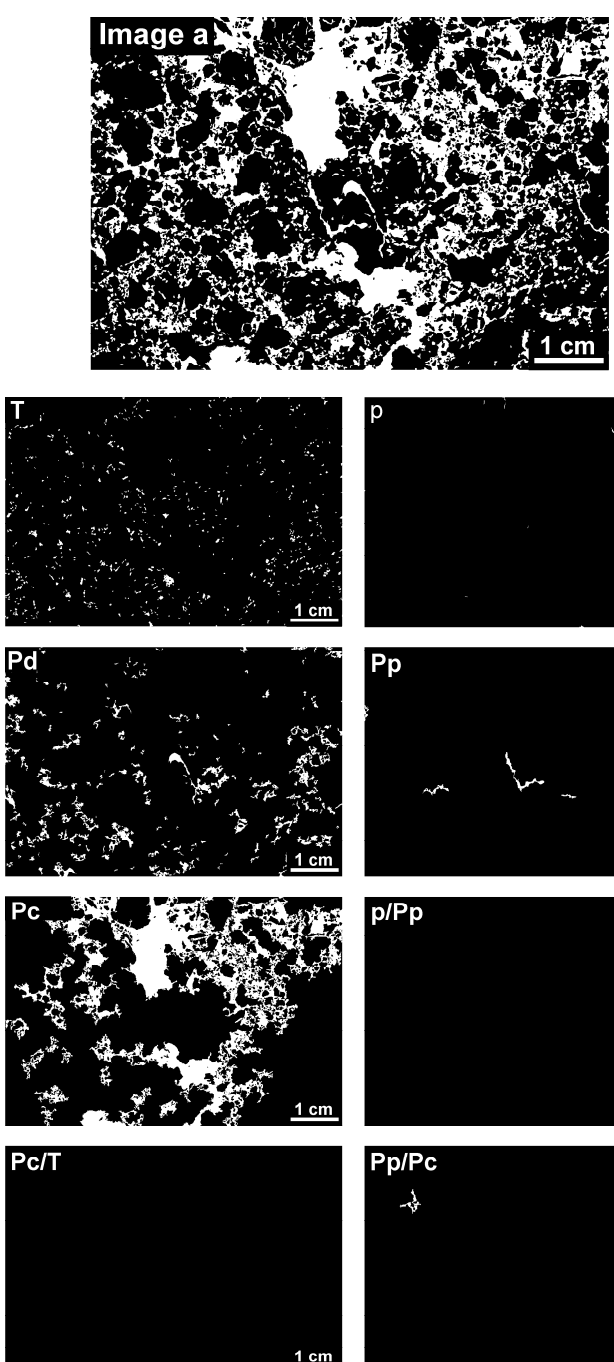
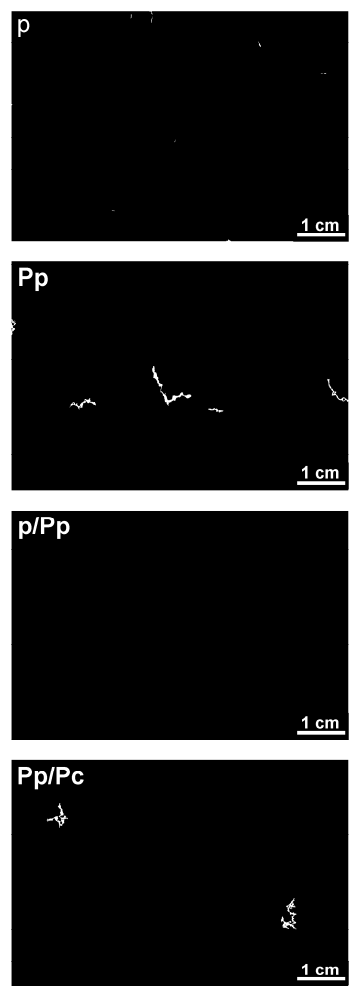
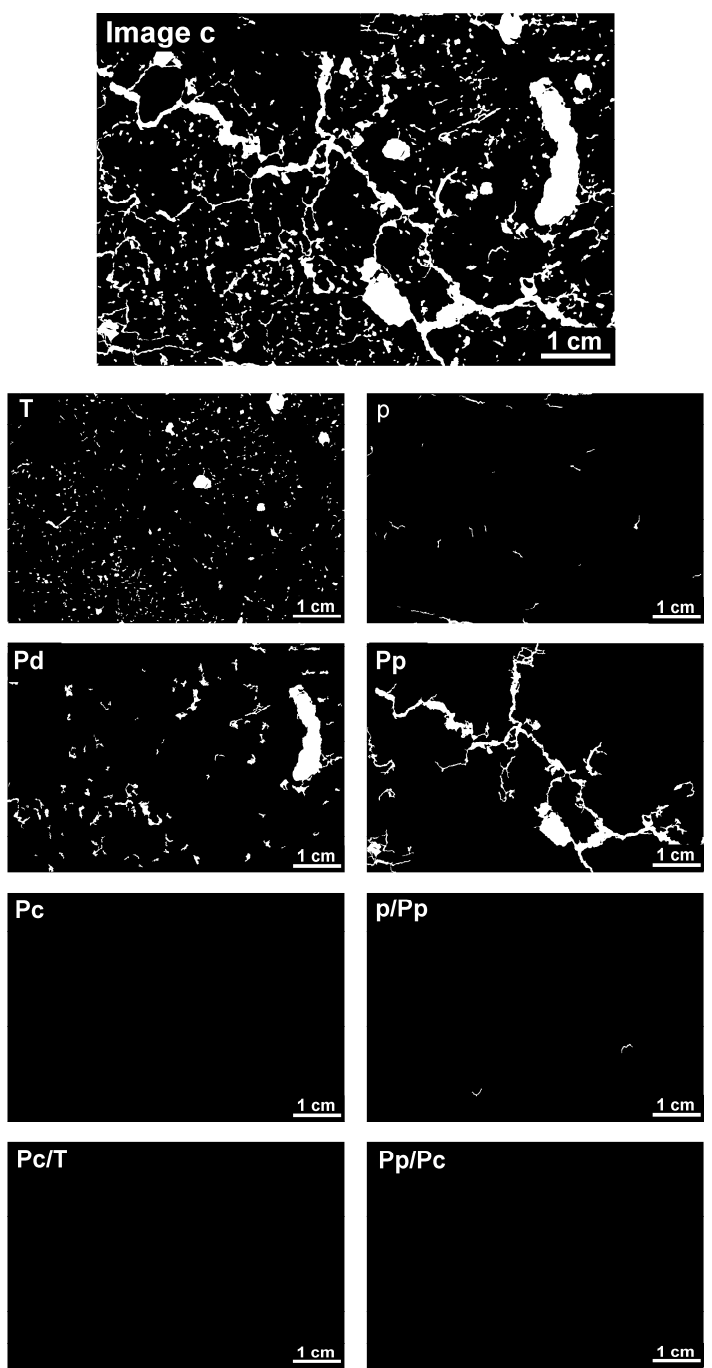
Figure 7: Class distribution of macroporosity for the three tillage practices at 2 depths (1-7 cm deep and 10-16 cm deep) on 06/28/2004. a-under conventional tillage ; b-under moderate tillage ; c-under no tillage.

Conventional tillage at $1 \mathrm{~cm}$ depth

a

Conventional tillage at $10 \mathrm{~cm}$ depth
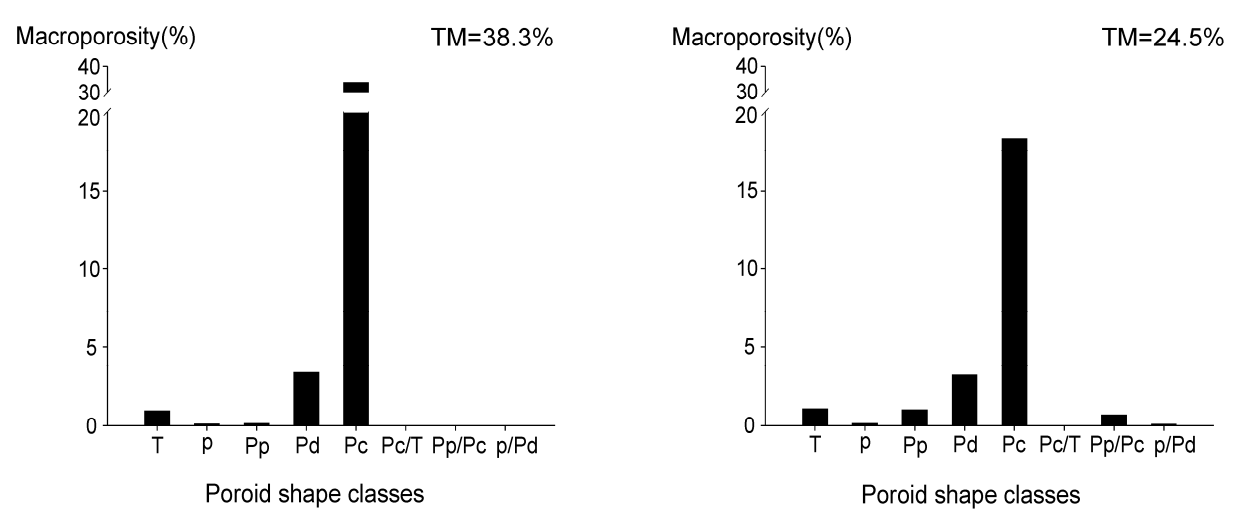

b

Moderate tillage at $1 \mathrm{~cm}$ depth

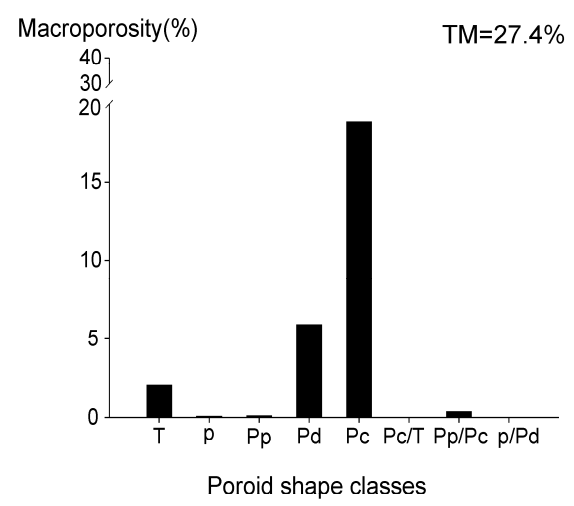

No tillage at $1 \mathrm{~cm}$ depth
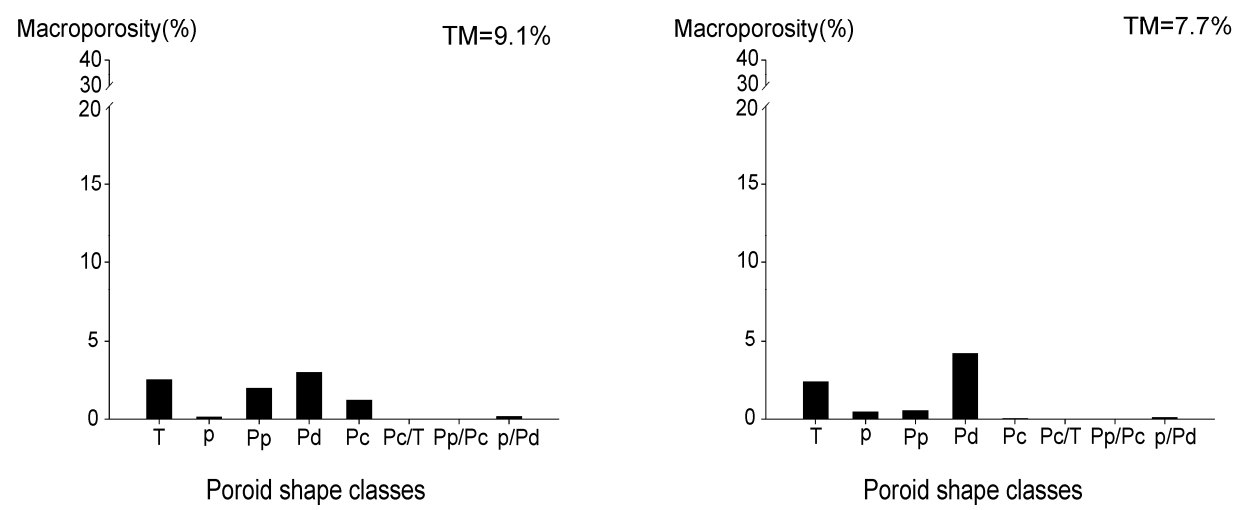
Figure 8: Evolution of the class distribution of macroporosity between 2 dates under conventional tillage and under no tillage. a-under conventional tillage between 06/15/2004 and 09/14/2004 ; b-under no tillage between 05/11/2004 and 09/14/2004.

a

Conventional tillage at $1 \mathrm{~cm}$ depth Macroporosity (\%)

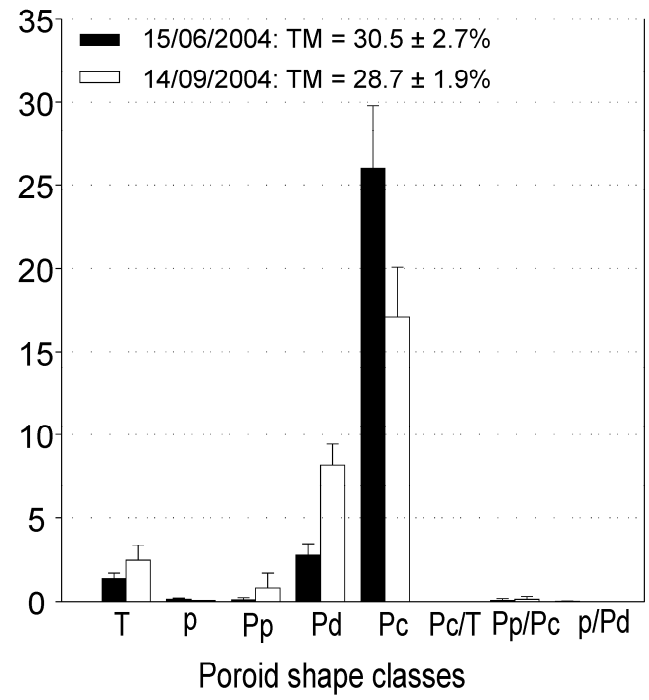

No tillage at $1 \mathrm{~cm}$ depth

Macroporosity (\%)

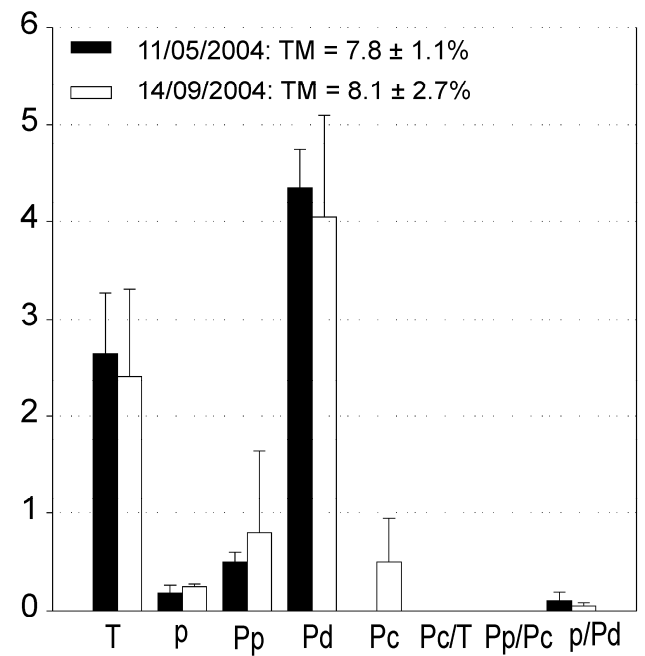

Poroid shape classes
Conventional tillage at $10 \mathrm{~cm}$ depth Macroporosity (\%)

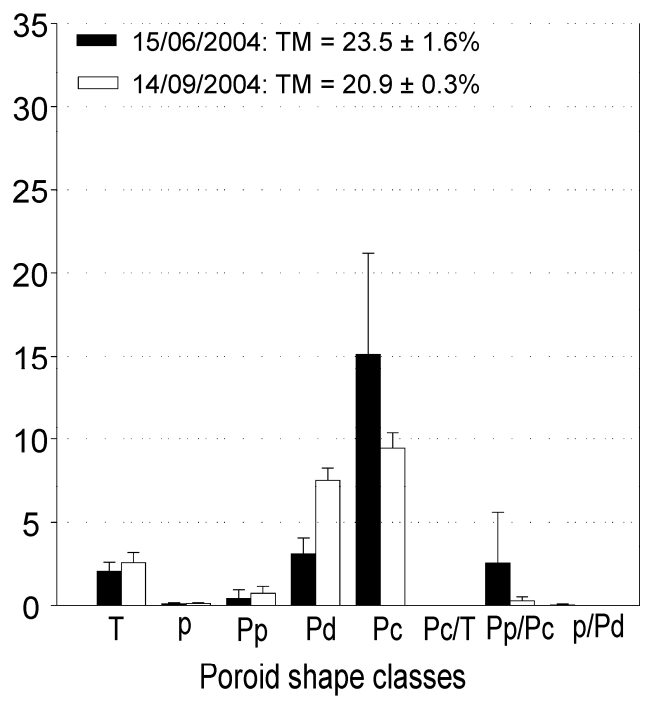

b

No tillage at $10 \mathrm{~cm}$ depth

Macroporosity (\%)

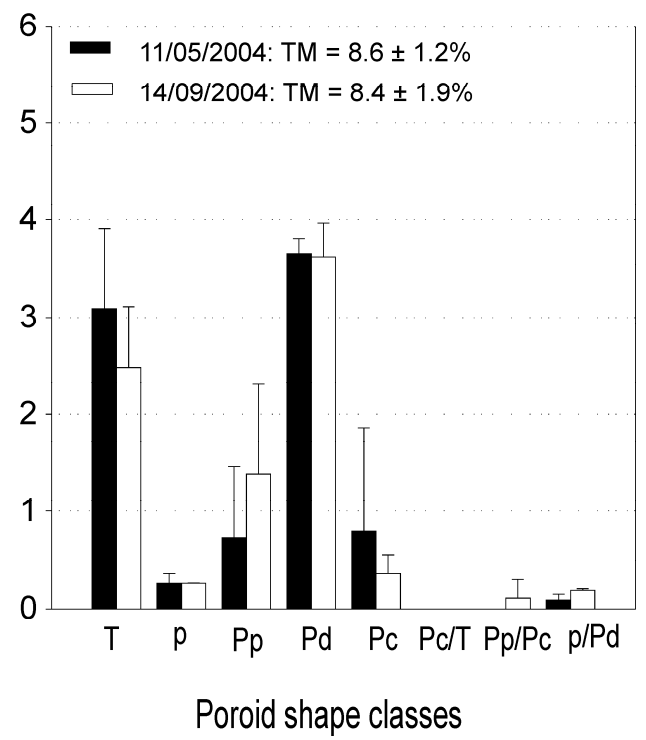


Figure 9: Greyscale images showing the evolution of the macroporosity under conventional tillage during the growing season between June and September. a-June: after mechanical fragmentation ; b-September: after biological fragmentation, during the growing season.

a
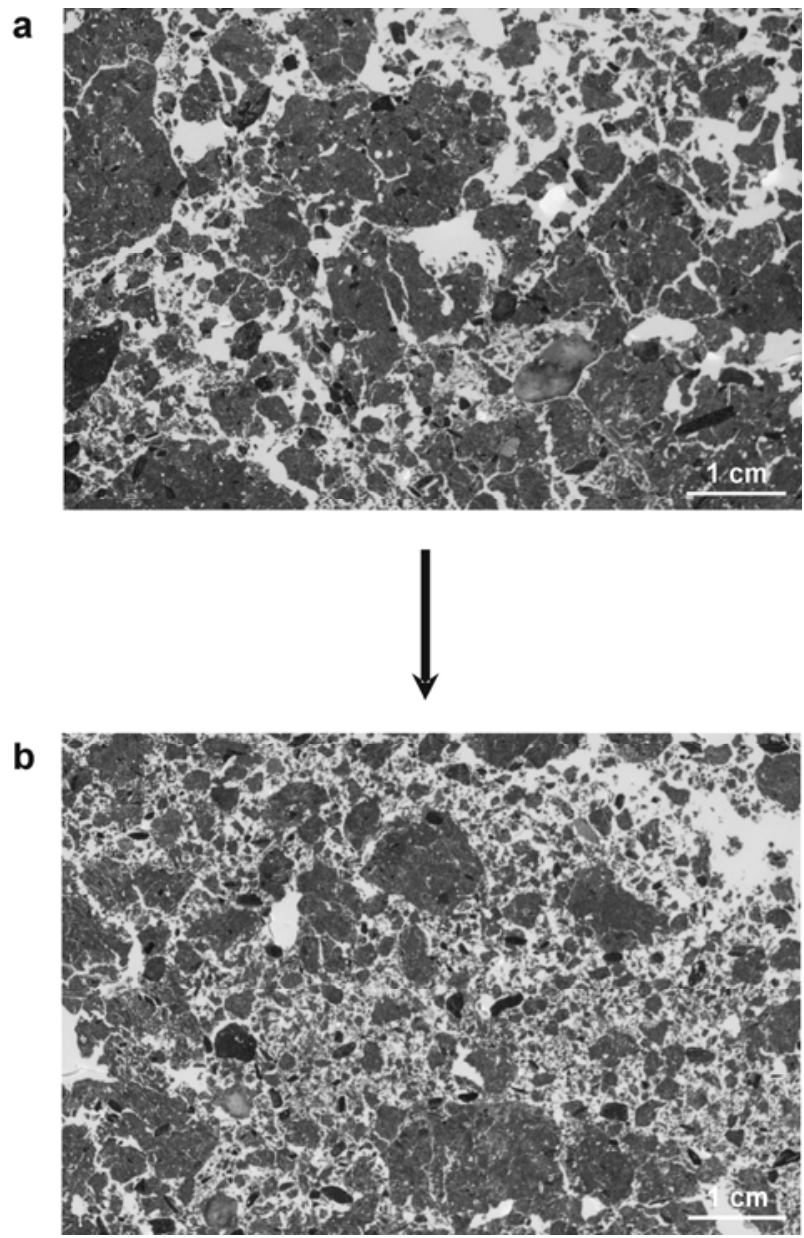